\title{
Responses of Physiological Traits and Nutritional Ingredients Content in Flowers of Medicinal Chrysanthemum to Selenium Application at Different Growth Stages
}

\author{
Jian-Zhou Chu, Xiao-Qin Yao*, Chao Si, Gui-Xia Liu, Chun-Hui Ma \\ The College of Life Sciences, Hebei University, Baoding, China \\ *Corresponding author: yaoxiao301@126.com
}

Received June 25, 2014; Revised August 25, 2014; Accepted September 04, 2014

\begin{abstract}
The paper mainly studied the effects of selenium (Se) application time on physiological traits and nutritional ingredients in flowers of medicinal chrysanthemum. Flower dry weight and Se concentration in flower were significantly increased by Se application at vigorous growth, bud differentiation and bud stages. Spraying Se at seedling and flower stages evidently increased Se concentration, but did not affect flower dry weight. The rate of superoxide radical production, hydrogen peroxide $\left(\mathrm{H}_{2} \mathrm{O}_{2}\right)$ and malondialdehyde concentration were significantly decreased by Se application at vigorous growth (except for $\mathrm{H}_{2} \mathrm{O}_{2}$ ), bud differentiation and bud stages. At five growth stages, Se application significantly increased glutathione peroxidase activity. At bud differentiation and bud stages, Se application significantly increased penylalanine ammonia lyase enzyme activity, chlorogenic acid, free amino acid and vitamin $\mathrm{C}$ content. These results indicated that Se applied at bud differentiation---bud stage was more beneficial for flower dry weight, Se concentration and nutritional ingredients content in flowers.
\end{abstract}

Keywords: chrysanthemum, selenium, chlorogenic acid, flavone, free amino acid

Cite This Article: Jian-Zhou Chu, Xiao-Qin Yao", Chao Si, Gui-Xia Liu, and Chun-Hui Ma, "Responses of Physiological Traits and Nutritional Ingredients Content in Flowers of Medicinal Chrysanthemum to Selenium Application at Different Growth Stages.” Journal of Food and Nutrition Research, vol. 2, no. 9 (2014): 575-581. doi: 10.12691/jfnr-2-9-8.

\section{Introduction}

Selenium (Se) is an essential trace element for human and animal nutrition, and is a component of some important seleno-proteins and enzymes in organisms. Many studies have indicated that Se in human has important physiological functions such as antioxidant defense, anti-cancer and anti-inflammatory effects [1]. However, Se deficiency in soil is overall distributed around the world [2], which directly affects Se concentration in plant, and can cause many diseases in human. Clinical medical trials have proved that about 40 kinds of diseases threatening human health were related to Se deficiency in human [3]. Thus, it is very important for improving Se deficient status in human by development of Se-enriched food.

In recent years, it was a hot study about increasing Se concentration in crops to meeting people's demand to Se element [4]. Researches have identified that the right amount of Se could not only increase Se concentration in plant, but also promote growth and development of plant under stressful or non-stressful conditions, although it has not been demonstrated to be required by higher plants $[5,6,7,8]$. Previous studies have been primarily done on grain crops and economic crops. However, only a small amount of work reported Se effects on medicinal plants. Tian and Wang [9] found that Se application (<1.0 $\mathrm{mg} \mathrm{kg}$ ${ }^{1}$ soil) significantly increased content and accumulation of Se, flavonoids and rutin in all organs of tartary buckwheat. The experiment performed by Dong et al. [1] showed that Se (0.01-0.05 $\mathrm{g} \mathrm{kg}^{-1}$ ) significantly increased chlorogenic acid by $200-400 \%$ in Lycium chinense leaves by adding sodium selenite to MS culture solution. These results indicated that Se could affect secondary metabolites content in plants. Most of active ingredients in medicinal plants are secondary metabolites. Modern pharmacological studies have shown that pharmacological effects of many medicinal plants are relevant with active ingredients content [10]. However, it is not clear how Se regulates secondary metabolism in medicinal plants. In addition, there have been limited efforts to know the effects of Se application time on medicinal plants. So, more works should be done for better knowing the roles of Se in medicinal plants.

The flowers of medicinal chrysanthemum (Chrysanthemum morifolium Ramat) are commonly used for tea and traditional Chinese medicine in China. Active and nutritional ingredients in flowers mainly include total flavone, chlorogenic acid, free amino acid, vitamin $\mathrm{C}$ and so on. Modern pharmacological researches have shown 
that flowers of medicinal chrysanthemum had a variety of functions including anti-bacterial, anti-inflammatory, antioxidant and anti-tumor properties etc. The paper primarily studied the effects of Se application time on physiological traits and nutritional ingredients content in flowers, in order to provide the basis for rational application of Se fertilizer and production of Se-enriched chrysanthemum.

\section{Materials and Methods}

\subsection{Plant Material and Experimental Design}

The research was conducted with pot experiments in Hebei University, Baoding, China. The seedlings of Huai chrysanthemum (little Huai chrysanthemum) were obtained from Jiaozuo Chinese herbal medicine planting base, Henan province, China $\left(35^{\circ} 14^{\prime} \mathrm{N}, 113^{\circ} 13^{\prime} \mathrm{E}\right)$. The seedlings of the same size were selected based on plant height. The average plant height was $9.58 \pm 0.32 \mathrm{~cm}$. Seedlings were transplanted into the plastic pots $(30-\mathrm{cm}$ diameter and $40 \mathrm{~cm}$ depth), one seedling per pot. The substrate was sieved topsoil from farmland. The content of soil organic matter, soil available $\mathrm{N}, \mathrm{P}$ and $\mathrm{K}$, and soil $\mathrm{pH}$ was $15.06 \mathrm{~g} \mathrm{~kg}^{-1}, 60.29 \mathrm{mg} \mathrm{kg}^{-1}, 25.36 \mathrm{mg} \mathrm{kg}^{-1}, 110.56 \mathrm{mg}$ $\mathrm{kg}^{-1}$, and 8.0, respectively. $\mathrm{N}\left(0.4 \mathrm{~g} \mathrm{~kg}^{-1}\right), \mathrm{P}\left(0.2 \mathrm{~g} \mathrm{P}_{2} \mathrm{O}_{5} \mathrm{~kg}^{-1}\right)$ and $\mathrm{K}\left(0.3 \mathrm{~g} \mathrm{~K}_{2} \mathrm{O} \mathrm{kg}{ }^{-1}\right)$ were added to the soil as base fertilizers to meet the nutrient demand of chrysanthemum growth.

Extra Se was supplied as sodium selenite $\left(\mathrm{Na}_{2} \mathrm{SeO}_{3}\right)$. The Se solution (30 $\left.\mathrm{mg} \mathrm{L}^{-1}\right)$ was sprayed one time at seedling $(8 / 5,2013)$, vigorous growth $(10 / 7,2013)$, flower bud differentiation $(18 / 9,2013)$, bud $(10 / 10,2013)$ and flower (19/10, 2013) stages of chrysanthemum, respectively. Spraying volume per pot was $100 \mathrm{~mL}$, and spraying time was selected in windless weather. Each treatment had four replications.

\subsection{Flower Yield}

Fresh flowers were harvested $(24 / 10,2013)$ and dried to a constant mass. Flower yield was expressed as g dry weight (DW) per plant.

\subsection{Selenium Concentration}

The dried flower was ground with grinding mill. About $0.5 \mathrm{~g}$ sample was digested with $10 \mathrm{~mL}$ of mixture of $\mathrm{HNO}_{3}$ and $\mathrm{HCLO}_{4}(4: 1, \mathrm{v} / \mathrm{v})$ at $150^{\circ} \mathrm{C}$ for $2 \mathrm{~h}$. After the digested solution was colorless, and cooled, $5 \mathrm{~mL}$ of $\mathrm{HCl}$ (1:1) was added to the digest solution to reduce $\mathrm{Se}^{6+}$ to $\mathrm{Se}^{4+}$. This process took $30 \mathrm{~min}$ until the sample was completely mineralized and transferred quantitatively to $50 \mathrm{~mL}$ volumetric flask. Se concentration was determined by atomic fluorescence spectrometry (AFS-830a, Beijing Jitian, Beijing, China). The measurement conditions were as follows: the voltage, $\mathrm{HCl}$ cathode current, carrier gas flow rate, the shielding gas flow rate, atomizer height, injection volume, reading time, and delayed time were 280 $\mathrm{V}, 80 \mathrm{~mA}, 300 \mathrm{~mL} \mathrm{~min}^{-1}, 500 \mathrm{~mL} \mathrm{m^{-1 }}, 8 \mathrm{~mm}, 0.5 \mathrm{~mL}$, $10 \mathrm{~s}$, and $1 \mathrm{~s}$, respectively.

\subsection{The Rate of Superoxide Radical Production, Hydrogen Peroxide and Malondialdehyde Concentration}

The rate of superoxide radical production $\left(\mathrm{O}_{2}{ }^{-}\right)$was measured as described by Ke et al. [11], by monitoring the nitrite formation from hydroxylamine in the presence of $\mathrm{O}_{2}{ }^{-} .0 .5 \mathrm{~g}$ sample were homogenized with $1.5 \mathrm{~mL}$ of 65 mmol L ${ }^{-1}$ potassium phosphate $(\mathrm{pH} 7.8)$ and centrifuged at $5000 \times \mathrm{g}$ for $10 \mathrm{~min}$. The incubation mixture contained $0.45 \mathrm{~mL}$ of $65 \mathrm{mmol} \mathrm{L}^{-1}$ phosphate buffer ( $\left.\mathrm{pH} 7.8\right), 0.5$ $\mathrm{mL}$ of $10 \mathrm{mmol} \mathrm{L}^{-1}$ hydroxylamine hydrochloride, and 0.5 $\mathrm{mL}$ of the supernatant. After incubation at $25{ }^{\circ} \mathrm{C}$ for 20 min, $0.5 \mathrm{~mL}$ of $8.5 \mathrm{mmol} \mathrm{L}^{-1}$ sulfanilamide and $0.5 \mathrm{~mL}$ of $3.5 \mathrm{mmol} \mathrm{L} \mathrm{L}^{-1} \alpha$-naphthylamine were added to the incubation mixture. After reaction at $25{ }^{\circ} \mathrm{C}$ for $20 \mathrm{~min}$, the absorbance of solution was measurement by spectrophotometer at $530 \mathrm{~nm}$. A standard curve with $\mathrm{NO}_{2}^{-}$ was used to calculate the production rate of $\mathrm{O}_{2}^{-}$from the chemical reaction of $\mathrm{O}_{2}^{-}$and hydroxylamine.

Hydrogen peroxide $\left(\mathrm{H}_{2} \mathrm{O}_{2}\right)$ concentration was determined according to Prochazkova et al. [12]. $0.5 \mathrm{~g}$ sample was ground with $5 \mathrm{~mL}$ cooled acetone in a cold room $\left(10^{\circ} \mathrm{C}\right)$. Mixture was filtered with filter paper followed by the addition of $2 \mathrm{~mL} \mathrm{5 \%}$ titanium sulfate and $5 \mathrm{~mL}$ ammonium solution to precipitate the titaniumhydrogen peroxide complex. The reaction mixture was centrifuged at $10000 \times \mathrm{g}$ for $10 \mathrm{~min}$. The precipitate was dissolved in $5 \mathrm{~mL}$ of $2 \mathrm{~mol} \mathrm{~L} \mathrm{~L}^{-1} \mathrm{H}_{2} \mathrm{SO}_{4}$ and then recentrifuged. The absorbance of supernatant was measurated by spectrophotometer at $415 \mathrm{~nm}$.

The degree of lipid peroxidation in leaf tissue was assessed by malondialdehyde (MDA) concentration. MDA concentration was determined by the thiobarbituric acid (TBA) reaction. $0.5 \mathrm{~g}$ sample was extracted with $5 \mathrm{~mL}$ of $20 \%(w / v)$ trichloroacetic acid (TCA). The homogenate was centrifuged at $3500 \times \mathrm{g}$ for $20 \mathrm{~min}$. $2 \mathrm{~mL}$ supernatant was added to $2 \mathrm{~mL}$ of $20 \%$ TCA containing $0.5 \%$ (w/v) thiobarbituric acid. The mixture was kept in boiling water bath for $30 \mathrm{~min}$ and then quickly cooled on ice. After refrigeration, the solution was centrifuged at $10000 \times \mathrm{g}$ for $15 \mathrm{~min}$. The absorbance of supernatant was measured at $532 \mathrm{~nm}$ and $600 \mathrm{~nm}$, respectively. The value for nonspecific absorption at $600 \mathrm{~nm}$ was subtracted from the value at $532 \mathrm{~nm}$. MDA concentration was calculated using MDA's extinction coefficient of $155 \mathrm{mmol}^{-1} \mathrm{~cm}^{-1}$. Results were expressed as $\mu \mathrm{mol} \mathrm{g}{ }^{-1}$ fresh weight (FW).

\subsection{Reduced Glutathione Concentration and Glutathione Peroxidase Activity}

The reduced glutathione (GSH) concentration in flowers was measured according to the method of Liu and Li [13]. $0.5 \mathrm{~g}$ sample was ground with $5 \mathrm{~mL}$ buffer solution (containing $5 \mathrm{mmol} \mathrm{L}^{-1}$ EDTA, 3\% TCA), and centrifuged at $5000 \times \mathrm{g}$ for $15 \mathrm{~min}$. $2 \mathrm{~mL}$ of supernatant, $2.5 \mathrm{~mL}$ of $0.2 \mathrm{~mol} \mathrm{~L}^{-1}$ potassium phosphate buffer solution $(\mathrm{pH} 7.0)$ and $0.1 \mathrm{~mL}$ of DTNB regent (5,5-dithiobis-2nitrobenzoicacid) were mixed. The absorbance of solution was measured at $412 \mathrm{~nm}$ using a spectrophotometer.

Glutathione peroxidase (GSH-Px; EC. 1.11.1.9) was measured according to the method of Cartes et al. [2]. 0.5 g sample was extracted by phosphate buffer ( $\mathrm{pH}$ 7.4) containing $1 \mathrm{mmol} \mathrm{L}^{-1}$ EDTA-2Na, 1\% PVP (polyvinyl pyrrolidone). The homogenate was centrifuged at $4000 \mathrm{r}$ for $10 \mathrm{~min}$, then $0.4 \mathrm{~mL}$ of supernatant was assayed for GSH-Px activity by DTNB photochemical method. The absorbance of solution was measured at $422 \mathrm{~nm}$ using a 
spectrophotometer within 3 min, and the enzyme activity was calculated as a decrease in GSH in the reaction time with respect to a non enzyme reaction.

\subsection{Penylalanine Ammonia Lyase Enzyme}

Penylalanine ammonia lyase enzyme (PAL, EC 4.3.1.5) activity was expressed as the content of trans-cinnamic acid generated from L-phenylalanine by PAL [13]. $0.5 \mathrm{~g}$ sample was ground with $5 \mathrm{~mL}$ of borate buffer $(\mathrm{pH} 8.7)$ containing $5 \mathrm{mmol} \mathrm{L}^{-1}$ mercaptoethanol and $0.1 \%$ polyvinylpolypyrrolidone. Extracts were centrifuged at 10 $000 \times \mathrm{g}$ for $15 \mathrm{~min}$ at $4{ }^{\circ} \mathrm{C}$. The supernatant was used for the analysis of PAL activity. The reaction mixture contained $0.5 \mathrm{~mL}$ of the supernatant, $1 \mathrm{~mL} 0.02 \mathrm{~mol} \mathrm{~L}^{-1} \mathrm{~L}$ phenylalanine and borate buffer $\left(0.05 \mathrm{~mol} \mathrm{~L}^{-1}, \mathrm{pH} 8.7\right)$ in a total volume of $3.0 \mathrm{~mL}$, and it was incubated at $30^{\circ} \mathrm{C}$ for $30 \mathrm{~min}$. The reaction was stopped by the addition of $1 \mathrm{~mL}$ $\mathrm{HCl}\left(2 \mathrm{~mol} \mathrm{~L}^{-1}\right)$. The absorbance of solution was measured at $290 \mathrm{~nm}$ using a spectrophotometer. The PAL activity was expressed as $\mu$ mol t-cinnamic acid $\mathrm{h}^{-1} \mathrm{~g}^{-1} \mathrm{FW}$.

\subsection{Total Flavone and Chlorogenic Acid Content}

Total flavone content was determined according to $\mathrm{He}$ and Liu [14] with minor modifications. $0.5 \mathrm{~g}$ sample was extracted with $20 \mathrm{~mL}$ of $50 \%$ ethanol solution in ultrasonic bath for $30 \mathrm{~min}$. The supernatant was filtered to a $50 \mathrm{~mL}$ volumetric flask and the volume was made up with $50 \%$ ethanol. $5 \mathrm{~mL}$ extracted solution was mixed with $8 \mathrm{~mL}$ of $1.5 \% \mathrm{AlCl}_{3}$ and $4 \mathrm{~mL}$ acetic acid-sodium acetate $(\mathrm{pH} 5.5)$, and the mixture volume was made up with $50 \%$ ethanol to $25 \mathrm{~mL}$. After $30 \mathrm{~min}$, the absorbance of solution was measured at $420 \mathrm{~nm}$. The flavone content was expressed as g rutin $100 \mathrm{~g}^{-1} \mathrm{DW}$.

Chlorogenic acid content was measured according to Zhang et al. [15]. $0.5 \mathrm{~g}$ sample was extracted with $20 \mathrm{~mL}$ of $50 \%$ methanol solution in ultrasonic bath for $30 \mathrm{~min}$. The supernatant was filtered to $50 \mathrm{~mL}$ volumetric flask. The filter residue was again extracted by the same method, and the volume was made up with $50 \%$ methanol to 50 mL. $5 \mathrm{~mL}$ extracted solution was mixed with $0.5 \mathrm{~mL}$ of $0.02 \mathrm{~mol} \mathrm{~L}^{-1} \mathrm{FeCl}_{3}$. After $60 \mathrm{~min}$, the absorbance of solution was measured at $755 \mathrm{~nm}$ and results were expressed as\% DW.

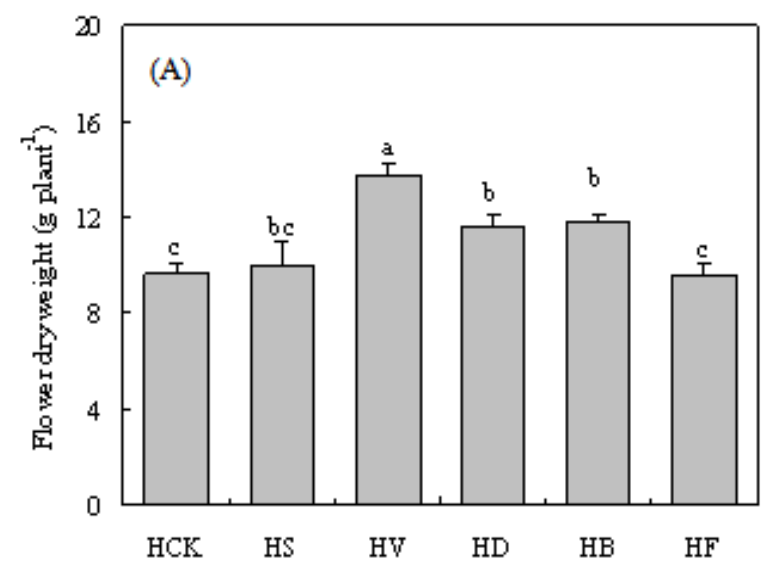

\subsection{Free Amino Acid and Vitamin $C$}

Free amino acid content was measured by ninhydrin colorimetric method. $0.5 \mathrm{~g}$ sample was extracted with 8 $\mathrm{mL}$ of $10 \%$ acetic acid solution in ultrasonic bath for 30 min. Extracts were centrifuged at $10000 \times \mathrm{g}$ for $10 \mathrm{~min} .2$ $\mathrm{mL}$ of the supernatant was mixed with $3 \mathrm{~mL}$ of ninhydrin and $0.1 \mathrm{~mL}$ of ascorbic acid. The mixture solution was heated in a water bath $\left(100^{\circ} \mathrm{C}\right)$ for $15 \mathrm{~min}$, and quickly cooled and shaken after water bath. When the solution turned to royal purple, the absorbance of solution was measured at $570 \mathrm{~nm}$ using a spectrophotometer and results were expressed as absorbance $\mu \mathrm{g} \mathrm{g}^{-1} \mathrm{DW}$

Vitamin C (ascorbic acid) content was determined by using the 2, 4-dinitrophenylhydrazine method (State Standard of the People's Republic of China, GB 1239290). $0.5 \mathrm{~g}$ sample was extracted with $10 \mathrm{~mL}$ of $1 \%$ oxalic acid solution in ultrasonic bath for $30 \mathrm{~min}$. The supernatant was filtered to $25 \mathrm{~mL}$ volumetric flask and the volume was made up with $1 \%$ oxalic acid. $10 \mathrm{~mL}$ supernatant was mixed with $0.5 \mathrm{~g}$ active carbon, fully shaken for $1 \mathrm{~min}$ and filtered again. $5 \mathrm{~mL}$ supernatant was mixed with $5 \mathrm{~mL}$ of $2 \%$ thiourea solution. Then, $4 \mathrm{~mL}$ mixed solution was added to $1.0 \mathrm{~mL}$ of $2 \% 2$, 4dinitrophenylhydrazine solution, and was kept in $37 \pm$ $0.5{ }^{\circ} \mathrm{C}$ water bath for $3 \mathrm{~h}$. After reaction, $5 \mathrm{~mL}$ of $85 \%$ sulfuric acid was gradually added to the reaction solution. The absorbance of solution was measured at $500 \mathrm{~nm}$, and results were expressed as mg $100 \mathrm{~g}^{-1} \mathrm{DW}$.

\subsection{Statistical Analysis}

Analyses were performed with the Software Statistical Package for the Social Science (SPSS) version 13.0. Homogeneity of variance was tested using the Levene test prior to analysis. Results were statistically analyzed using one-way ANOVA, followed by Duncan's test to determine whether they were significantly different at the 0.05 probability level.

\section{Results}

\subsection{Flower Dry Weight and Se Concentration in Flower}

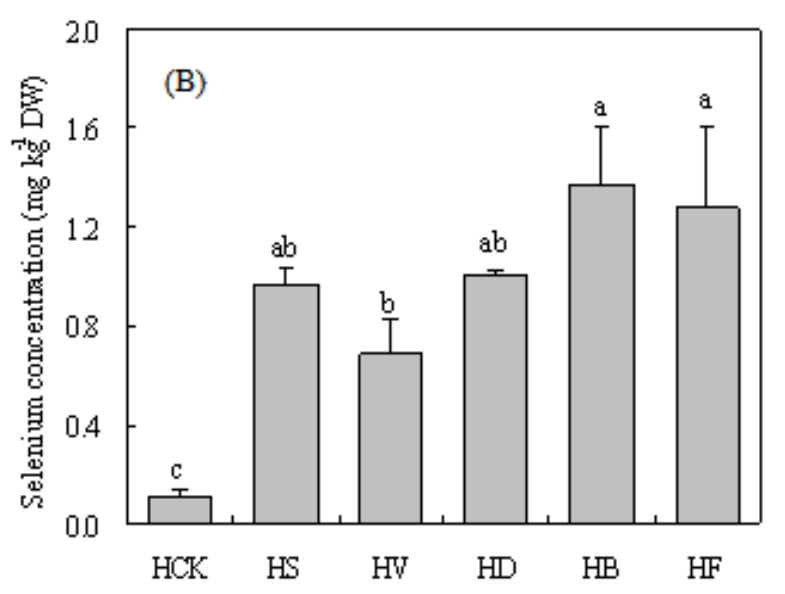

Figure 1. Effects of Se application on flower dry weight (A) and Se concentration (B) in flower of chrysanthemum. The bars with different letters are significantly different from each other $(P<0.05)$. Values are means of four replicates \pm SE. HCK, the control; HS, Se application at seedling stage; HV, Se application at vigorous growth stage; HD, Se application at flower bud differentiation stage; HB, Se application at bud stage; HF, Se application at flower stage 
The effects of Se on flower dry weight depended on Se application time (Figure 1A). At vigorous growth, flower bud differentiation and bud stages, Se application significantly increased flower dry weight compared with the control, and the increased amount induced by Se applied at vigorous growth stage was more than that at the other stages. However, Se application at seedling and flower stages did not evidently affect flower biomass accumulation. Se concentration in flower was significantly increased by Se application at different growth stages (Figure 1B).

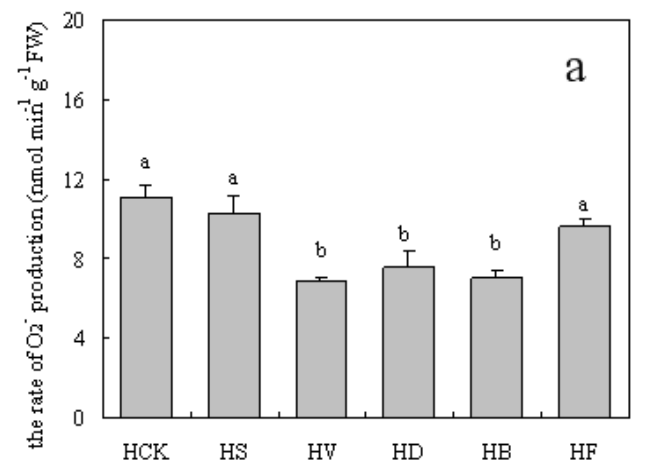

\subsection{The Rate of $\mathrm{O}_{2}^{-}$Production, $\mathrm{H}_{2} \mathrm{O}_{2}$ and MDA Concentration}

Compared with the control, Se treatment induced a significant decrease in the rate of $\mathrm{O}_{2}^{-}$production, $\mathrm{H}_{2} \mathrm{O}_{2}$ and MDA concentration at vigorous growth (except for $\mathrm{H}_{2} \mathrm{O}_{2}$ concentration), flower bud differentiation and bud stages (Figure 2). However, the rate of $\mathrm{O}_{2}{ }^{-}$production, $\mathrm{H}_{2} \mathrm{O}_{2}$ and MDA concentration in flower were not affected by Se applied at seedling and flower stages.
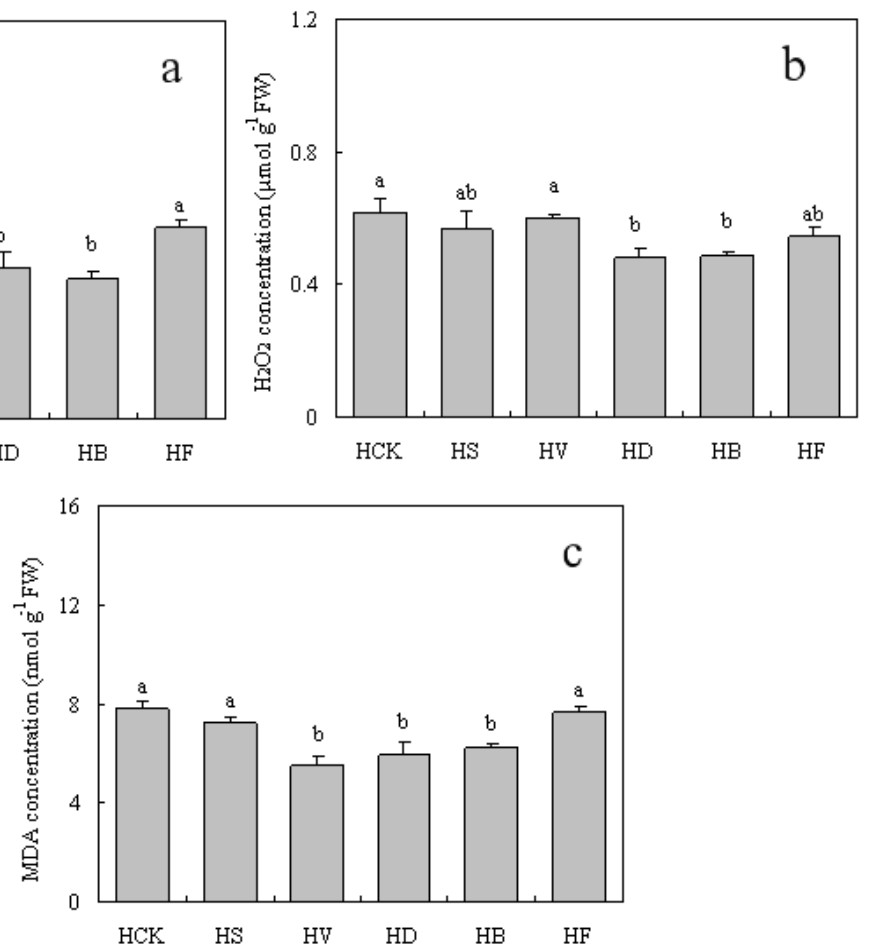

Figure 2. Effects of Se application on the rate of $\mathrm{O}_{2}{ }^{-}$production (A), $\mathrm{H}_{2} \mathrm{O}_{2}$ (B) and MDA (C) concentration in flower of chrysanthemum. The bars with different letters are significantly different from each other $(P<0.05)$. Values are means of four replicates \pm SE. HCK, the control; HS, Se application at seedling stage; HV, Se application at vigorous growth stage; HD, Se application at flower bud differentiation stage; HB, Se application at bud stage; HF, Se application at flower stage
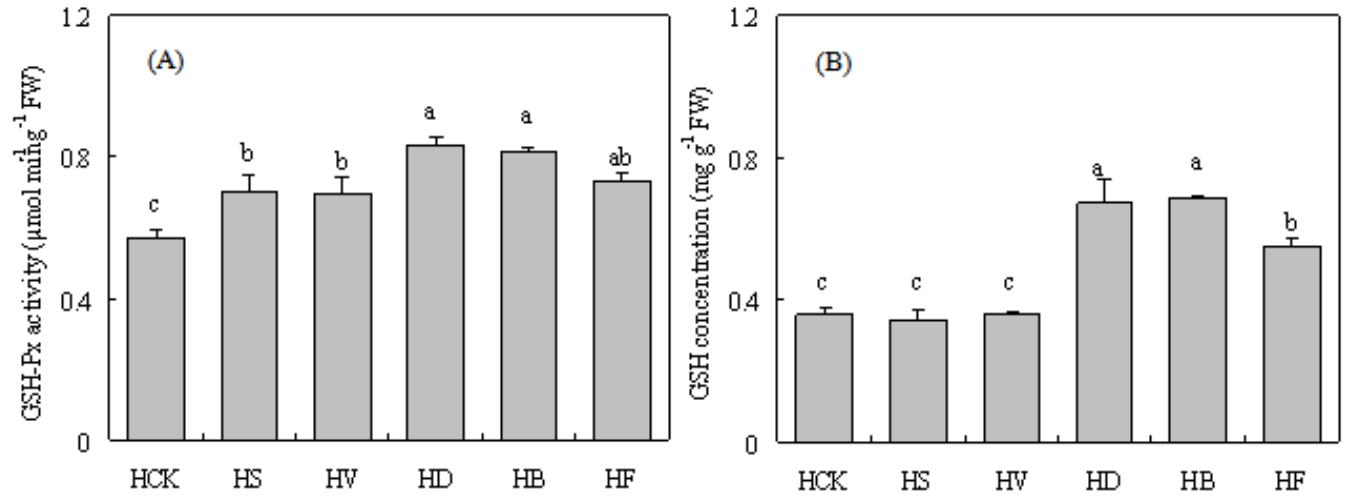

Figure 3. Effects of Se application on GSH-Px activity (A) and GSH concentration (B) in flower of chrysanthemum. The bars with different letters are significantly different from each other $(P<0.05)$. Values are means of four replicates \pm SE. HCK, the control; HS, Se application at seedling stage; HV, Se application at vigorous growth stage; HD, Se application at flower bud differentiation stage; HB, Se application at bud stage; HF, Se application at flower stage.

\subsection{GSH-Px Activity and GSH Concentration}

Figure 3A indicated that Se applications significantly increased GSH-Px activity in flower over the control, and GSH-Px activity in flower induced by spraying Se at flower bud differentiation and bud stages was higher than that at seedling and vigorous growth stages.

GSH concentration in flower was significantly increased by Se application at flower bud differentiation, bud and flower stages over the control (Figure 3B). At seedling and vigorous growth stages, Se application did not significantly affect GSH concentration. 


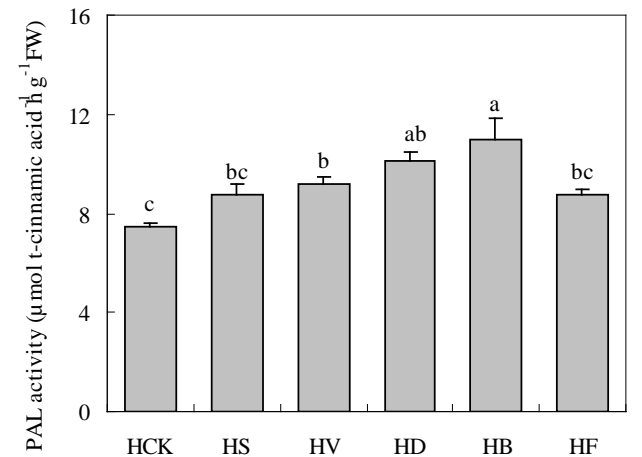

Figure 4. Effects of Se application on PAL activity in flower of chrysanthemum. The bars with different letters are significantly different from each other $(P<0.05)$. Values are means of four replicates $\pm \mathrm{SE}$. HCK, the control; HS, Se application at seedling stage; HV, Se application at vigorous growth stage; HD, Se application at flower bud differentiation stage; HB, Se application at bud stage; HF, Se application at flower stage

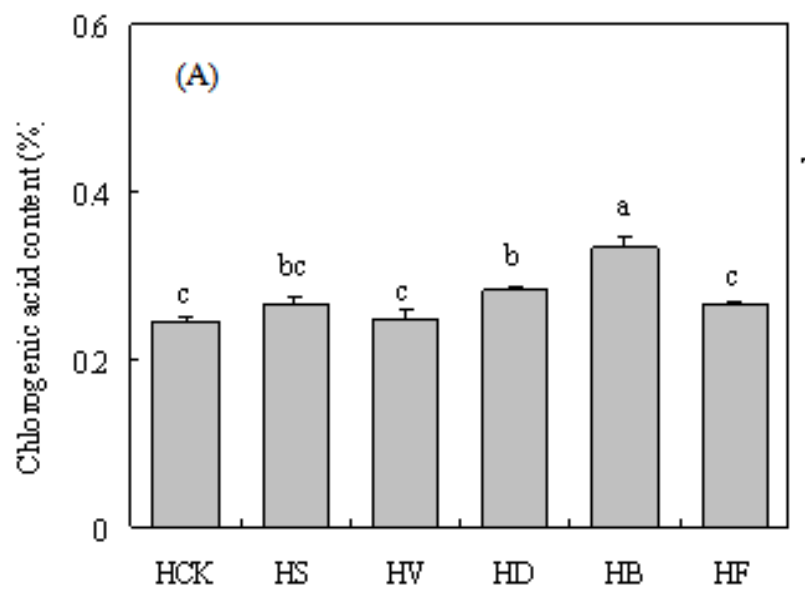

\subsection{PAL Activity}

Spraying Se at vigorous growth, flower bud differentiation and bud stages significantly increased PAL activity in flower compared with the control (Figure 4). However, PAL activity was not induced by Se treatments at seedling and flower stages.

\subsection{Total Flavone and Chlorogenic Acid Content}

Se applied at flower bud differentiation and bud stages induced a significant increase in chlorogenic acid content of flower, and chlorogenic content at the two stages was higher than that at seedling and vigorous growth stages (Figure 5A). Se application did not significantly affect flavone content in flower (Figure 5B).

Figure 5. Effects of Se application on chlorogenic acid (A) and flavone content (B) in flower of chrysanthemum. The bars with different letters are significantly different from each other $(P<0.05)$. Values are means of four replicates \pm SE. HCK, the control; HS, Se application at seedling stage; HV, Se application at vigorous growth stage; HD, Se application at flower bud differentiation stage; HB, Se application at bud stage; HF, Se application at flower stage
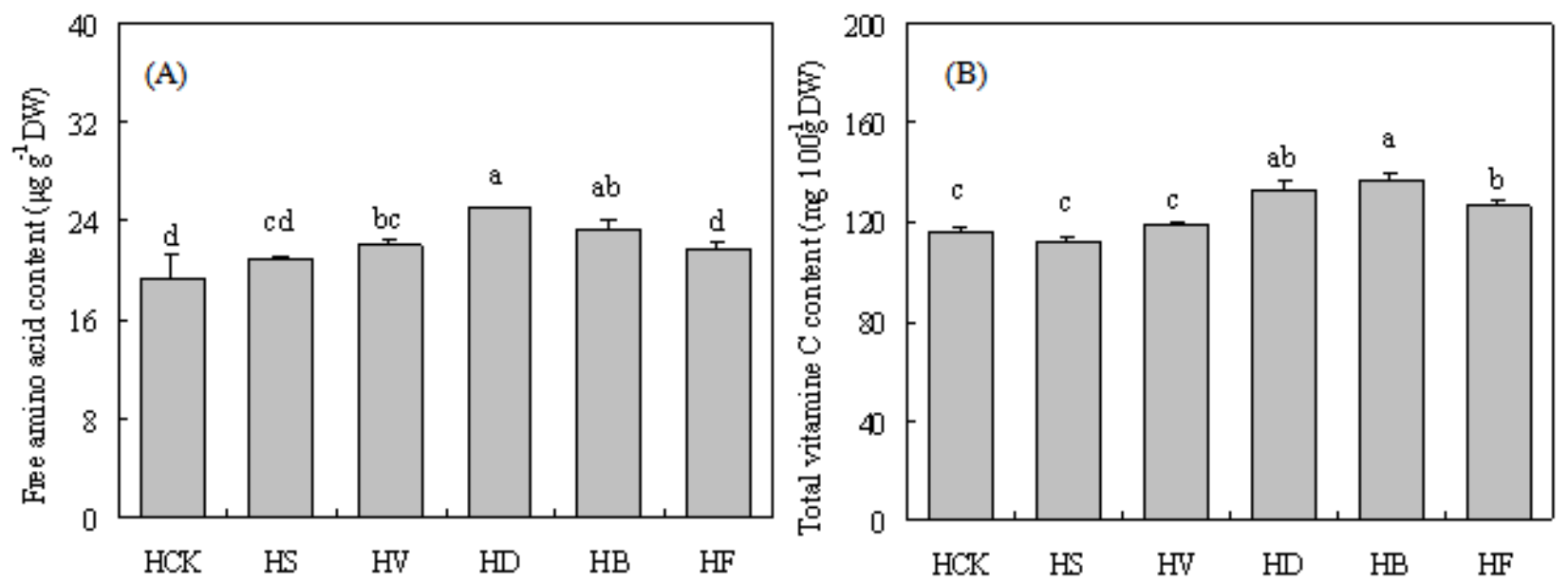

Figure 6. Effects of Se application on free amino acid (A) and vitamin C (B) content in flower of chrysanthemum. The bars with different letters are significantly different from each other $(P<0.05)$. Values are means of four replicates \pm SE. HCK, the control; HS, Se application at seedling stage; HV, Se application at vigorous growth stage; HD, Se application at flower bud differentiation stage; HB, Se application at bud stage; HF, Se application at flower stage

\subsection{Free Amino Acid and Vitamin C Content}

Spraying Se at flower bud differentiation and bud stages induced a significant increase in free amino and vitamin $C$ content of flower over the control (Figure 6). In addition, free amino in flower was significantly increased by Se applied at vigorous growth stage and vitamin $\mathrm{C}$ content at flower stage. 


\section{Discussion}

Many researches have proved that appropriate Se was beneficial for growth and development of plants under stressful or non-stressful conditions $[7,9,16,17,18]$. In the study, Se effects on flower biomass of chrysanthemum depended on Se application time. Se applied at vigorous growth, flower bud differentiation and bud stages significantly increased flower biomass accumulation (Figure 1A), which increased the commercial value of medicinal chrysanthemum to some extent. Se concentration in flower was evidently increased by Se application at different growth stages (Figure 1B), and there was no obvious difference between treatments (except for vigorous growth stage). However, in the experiments performed by Curtin et al. [19] and Chu et al. [7], Se concentration in grains induced by Se spraying at the later growth stages was more than that at the earlier growth stages. These results indicated that accumulation capacity of reproductive organs to Se not only depended on Se spraying time, but also was related to plant species.

It is generally accepted that the negative effects of stressful environment on plant is mainly caused by excessive production of reactive oxygen species (ROS), such an $\mathrm{H}_{2} \mathrm{O}_{2}$ and $\mathrm{O}_{2}{ }^{-}[20,21]$. Many papers have reported that Se application could reduce the oxidative stress in plants under abiotic stresses, such as cold, drought, enhanced UV-B radiation and salt stress [22,23]. In the experimental conditions, Se applied at vigorous growth (except for $\mathrm{H}_{2} \mathrm{O}_{2}$ ), flower bud differentiation and bud stages significantly decreased $\mathrm{H}_{2} \mathrm{O}_{2}$ concentration and the rate of $\mathrm{O}_{2}^{-}$production in flower (Figure 2A, Figure 2B), which partly explained why a decrease in MDA concentration was found at the three stages (Figure 2C). MDA concentration is commonly used to indicate the level of lipid peroxidation in plant [24]. The decreased MDA concentration indicated that Se application could alleviate membrane lipid peroxidation in flower of chrysanthemum to some extent, which was beneficial to growth and development of chrysanthemum.

In order to balance and control ROS toxicity in plants caused by stressful environment, plants also form some protective mechanisms by increasing antioxidant enzymes' activities and nonenzymatic antioxidants concentration. GSH-Px is a key enzyme of the ascorbateglutathione cycle that protects cells against oxidative damage maintaining a high GSH/GSSG ratio [25]. Previous studies commonly agreed that Se application could increase GSH-Px activity in leaves [2,24]. Similarly, our results indicated that Se sprayed at different growth stages also significantly increased GSH-Px activity in flower of chrysanthemum (Figure 3A), which might lead to the reduced ROS concentration and lipid peroxidation in flower (Figure 2A, Figure 2B)

PAL is a key enzyme of secondary metabolism that catalyzes the deamination of L-phenylalanine to transcinnamic acid. The carbon skeleton of cinnamic acid serves as a major substrate for many pathways of phenolic biosynthesis in plants [26]. The study performed by Tian and Wang [9] indicated that Se concentration was significantly related to PAL activity $(r=0.9973)$ in leaves of tartary buckwheat. In this study, Se application significantly increased PAL activity in flower at vigorous growth, flower bud differentiation and bud stages, indicating that Se application promoted the processes of secondary metabolism in flower at the three growth stages (Figure 4).

Many studies have shown that pharmacological effects of medicinal plants were relevant with secondary metabolites content [10]. Flavone and chlorogenic acid are the main active ingredients in many herb plants, which have many bioactivities, such as anti-bacterial, anti-cancer, anti-hiv and anti-oxidation effects, and can be easily absorbed in human body. In the experiment performed by Dong et al. [1], there was high correlation between Se and chlorogenic acid content in Lycium chinense leaves. In the study, Se application significantly increased chlorogenic acid content in flower of chrysanthemum at flower bud differentiation and bud stages (Figure 5A), further suggesting that Se might activate the activity of the enzyme synthesizing chlorogenic acid from caffeic acid in plants. Se sprayed at different growth stages did not significantly affect flavone content (Figure 5B). However, Li et al. [18] reported that Se added to soil significantly increased flavone content in flower of chrysanthemum. Therefore, more works should be done to explore the mechanism of Se-regulating secondary metabolism in plants.

Except for the active ingredients, flower of chrysanthemum also contains some nutrition, such as vitamins, amino acids and soluble sugar. Pharmacological effects and tea flavor of chrysanthemum might be the result of the comprehensive effects of various components. Amino acids play a vital role in the aroma of tea [16]. Ježek et al. [27] reported that spraying Se increased the relative content of total essential and non-essential amino acids in potato tuber at the tuberisation relative to the control, and the increase in phenylalanine content was particularly significant. In the study, spraying Se at vigorous growth, flower bud differentiation and bud stages increased total amino acid content in flower of chrysanthemum (Figure 6A), suggesting that the effects of Se on amino acid metabolism in flower depended on application time.

Vitamin C commonly exists in plant tissues, which can be used as substrates for the enzyme to scavenge active oxygen, protecting plant from the oxidative damage [28]. Lee et al. [29] reported that the vitamin C content of endive leaf tissues increased in response to increasing sodium selenate concentration added to solution. However, vitamin C content decreased linearly with increasing sodium selenite concentrations. Duma et al. [30] reported that sodium selenate added to peat substrate increased vitamin $\mathrm{C}$ concentration more efficient in comparison with selenite. The study performed by $\mathrm{Hu}$ et al. [16] indicated that green tea sprayed with selenium fertilizer significantly increased vitamin C content over the control, and no significant difference was found between fertilizers of selenite and selenate. Our results indicated that spraying sodium selenite at flower bud differentiation, bud and flower stages significantly increased vitamin $C$ in flower of chrysanthemum (Figure 6B), suggesting that Se effects on vitamin $\mathrm{C}$ in plants was not only affected by Se forms and Se application method, but depended on plant species and Se application time.

\section{Conclusions}


The effects of Se on flower yield and nutritional ingredients content in flowers of chrysanthemum depended on Se application time. Se applied at bud differentiation and bud stages significantly increased flower yield, Se concentration, chlorogenic acid, free amino acid and vitamin $\mathrm{C}$ content in flower of chrysanthemum. The study provided the basis for rational application of Se fertilizer and production of Se-enriched chrysanthemum.

\section{Acknowledgments}

This study was supported by Natural Science Foundation of Hebei Province (No. C2012201080), National Natural Science Foundation of China (No. 31300321 and No. 31072069).

\section{Statement of Competing Interests}

The authors have no competing interests.

\section{Reference}

[1] Dong, J.Z., Wang, Y., Wang, S.H., Yin, L.P., Xu, G.J., Zheng, C., Lei, C. and Zhang, M.Z., "Selenium increases chlorogenic acid, chlorophyll and carotenoids of Lycium chinense leaves,” Journal of the Science of Food and Agriculture, 93 (2), 310-315, 2013.

[2] Cartes, P., Gianfreda, L., Paredes, C. and Mora, M.L., "Selenium uptake and its antioxidant role in ryegrass cultivars as affected by selenite seed pelletization," Journal of Soil Science and Plant Nutrition, 11 (4), 1-14, 2011.

[3] Schrauzer, G.N. and Meginness, J.E., "Observations on human selenium supplementation”. Trace Substances and Environmental Health, 13, 64-82, 1978.

[4] Chilimba, A.D.C., Young, S., Black, C.R., Meacham, M.C., Lammel, j. and Broadley, M.R., "Agronomic biofortification of maize with selenium (Se) in Malawi,” Field Crops Research, 125, 118-128, 2012.

[5] Hartikainen, H. and Xue, T., "The promotive effect of selenium on plant growth as triggered by ultraviolet radiation," Journal of Environmental Quality, 28 (4), 1372-1375, 1999.

[6] Hu, H.F., Hu, C.X., Jie, X.L., Liu, S.L., Guo, X., Hua, D.L., Ma, C.A., Lu, J.W. and Liu, H.G., "Effects of selenium on herbage yield, selenium nutrition and quality of alfalfa," Journal of Agricultura and Food Chemistry, 8 (2), 792-795, 2010.

[7] Chu, J.Z., Yao, X.Q., Yue, Z.W., Li, J.M. and Zhao, J.H., “The effects of selenium on physiological traits, grain selenium concentration and yield of winter wheat at different development stages,” Biological Trace Element Research, 151 (3), 434-440, 2013.

[8] Feng, R.W., Wei, C.Y. and Tu, S.X., “The roles of selenium in protecting plants against abiotic stresses,” Environmental and Experimental Botany, 87, 58-68, 2013.

[9] Tian, X.Y. and Wang, Z.Y., "Effects of selenium application on content, distribution and accumulation of selenium, flavonoids and rutin in tartary buckwheat,” Plant Nutrition and Fertilizer Science, 14 (4), 721-727, 2008 (in Chinese).

[10] Wu, Y., Fang, M.F., Yue, M., Chai, Y.F., Wang, H. and Li, Y.F., "Advances in influence of UV-B radiation on medicinal plant secondary metabolism,” Zhongguo Zhong Yao Za Zhi, 37 (15), 2248-2251, 2012 (in Chinese).

[11] Ke, D., Wang, A., Sun, G. and Dong, L., "The effect of active oxygen on the activity of ACC synthase induced by exogenous IAA”. Acta Botanica Sinica, 44 (5), 551-556, 2002.
[12] Prochazkova, D., Sairam, R.K., Srivastava, G.C. and Singh, D.V., "Oxidative stress and antioxidant activity as the basis of senescence in maize leaves,” Plant Science, 161 (4), 765-771. 2001.

[13] Li, H.S., The experimental principle and technology in plant physiology and biochemistry, Higher Education Press, Beijing, 2000, 213-214.

[14] He, S.M. and Liu, J.L., "Study on the Determination Method of Flavone Content in Tea," Chinese Journal of Analytical Chemistry, 35 (9), 1365-1368, 2007.

[15] Zhang, Q.F., Liu, B., Shi, H. and Huang, S.F., "Rapid determination of chlorogenic acid in flowers of Lonicera japonica,” Journal of Fujian Medical University, 40 (4), 398-401, 2006 (in Chinese).

[16] $\mathrm{Hu}, \mathrm{Q} ., \mathrm{Xu}, \mathrm{J}$. and Pang, G., "Effect of selenium on the yield and quality of green tea leaves harvested in early spring," Journal of Agricultura and Food Chemistry, 51 (11), 3379-3381, 2003.

[17] Kong, L.G., Wang, M. and Bi, D., "Selenium modulates the activities of antioxidant enzymes, osmotic homeostasis and promotes the growth of sorrel seedlings under salt stress," Plant Growth Regulation, 45 (2), 155-163, 2005.

[18] Li, Y.M., Sun, Y.X. and Li, D.H., "Effects of applying selenium on contents of total flavonoid, chlorogenic acid and selenium in flower of Chrysanthemum morifolium,” Soil, 42, 618-623, 2010 (in Chinese).

[19] Curtin, D., Hanson, R., Lindley, T.N. and Butler, R.C., "Selenium concentration in wheat (Triticum aestivum) grain as influenced by method, rate, and timing of sodium selenite application," New Zealand Journal of Crop and Horticultural Science, 34 (4), 329339, 2006.

[20] Pruvot, G., Masimino, J., Peltier, G. and Rey, P., "Effects of low temperature, high salinity and exogenous ABA on the synthesis of two chloroplastic drought-induced proteins in Solanum tuberosum,” Physiologia Plantarum, 97 (1), 123-131, 1996.

[21] Santos, I., Fidalgo, F. and Almeida, J.M., "Biochemical and ultrastructural changes in leaves of potato plants grown under supplementary UV-B radiation,” Plant Science, 167, 925-935, 2004.

[22] Hawrylak-Nowak, B., "Beneficial effects of exogenous selenium in cucumber seedlings subjected to salt stress," Biological Trace Element Research, 132 (1-3), 259-269, 2009.

[23] Chu, J.Z., Yao, X.Q. and Zhang, Z.N., "Responses of wheat seedlings to exogenous selenium supply under cold stress," Biological Trace Element Research, 136 (3), 355-363, 2010.

[24] Ríos, J.J., Blasco, B., Cervilla, L.M., Rosales, M.A., SanchezRodriguez, E., Romero, L. and Ruiz, J.M., "Production and detoxification of $\mathrm{H}_{2} \mathrm{O}_{2}$ in lettuce plants exposed to selenium," Annals of Applied Biology, 154 (1), 107-116, 2009.

[25] Foyer, C. and Noctor, G., “Oxidant and antioxidant signaling in plants: a re-evaluation of the concept of oxidative stress in a physiological context,” Plant, Cell and Environment, 28 (8), 10561071, 2005.

[26] Zucker, M., "Induction of phenylalanine ammonia-lyase in xanthium leaf disks. Photosynthetic requirement and effect of daylength,” Plant Physiology, 44 (6), 912-922, 1969.

[27] Ježek, P., Hlušek, J., Lošák, T., Jůzl, M., Elzner, P., Kráčmar, S., Buňka, F. and Martensson, A., "Effect of foliar application of selenium on the content of selected amino acids in potato tubers (Solanum tuberosum L.)," Plant, Soil and Environment, 57, 315320, 2011.

[28] Niki, E., "Action of ascorbic acid as a scavenger of active and stable oxygen radicals," The American Journal of Clinical Nutrition, 54 (6 Suppl), 1119S-1124S, 1991.

[29] Lee, G.P. and Par, K.W., "Effect of selenium concentration in the nutrient solution on the growth and internal quality of endive," Journal of the Korean Society for Horticultural Science, 39, 391396, 1998.

[30] Duma, M., Alsina, I., Dubova, L., Stroksa, L. and Smiltina, Z. "The effect of sodium selenite and selenite on the quality of lettuce," in Baltic Conference on Food Science and Technology, FoodBalt. Jelgave (Latvia), 39-44. 